\title{
Spatial Distribution and Dispersal Patterns of Central North American Freshwater Crayfish (Decapoda: Cambaridae) with Emphasis on Implications of Glacial Refugia
}

\author{
Thomas P. Simon ${ }^{1,2}$ and Jacob L. Burskey ${ }^{1,2}$ \\ ${ }^{1}$ Department of Biology, Indiana State University, 600 Chestnut Street, Terre Haute, IN 47809, USA \\ ${ }^{2}$ Indiana Biological Survey, Aquatic Research Center, 6440 South Fairfax Road, Bloomington, IN 47401, USA \\ Correspondence should be addressed to Thomas P. Simon; thomas_simon@juno.com
}

Received 31 May 2014; Revised 8 October 2014; Accepted 13 October 2014; Published 6 November 2014

Academic Editor: Arianna Azzellino

Copyright (c) 2014 T. P. Simon and J. L. Burskey. This is an open access article distributed under the Creative Commons Attribution License, which permits unrestricted use, distribution, and reproduction in any medium, provided the original work is properly cited.

\begin{abstract}
Spatial distributions of crayfish were evaluated in relation to glacial geography and possible modes of dispersal from refugia. Species dispersal patterns were a priori hypothesized and tested using principle components analysis (PCA). PCA factor loading plots were evaluated for hypothesized crayfish dispersal patterns. Cambarus laevis was limited to the unglaciated region, while Orconectes immunis, Orconectes virilis, and Procambarus gracilis may have dispersed from western glacial refugia in the upper Missouri drainage. Fallicambarus fodiens and Procambarus acutus dispersed from south of the glacial advance within the Mississippi embayment. Previous dispersal hypotheses for Orconectes propinquus recognized that northern refugia may have been from the Driftless Area in Wisconsin and Illinois and may have invaded more than one refuge since this species was common in unglaciated areas of southwestern Indiana. Orconectes indianensis center of abundance is in the unglaciated region. Disjunct populations likely dispersed into temporary glacial lakes that, when receded, left populations in previously glaciated areas. Cambarus polychromatus possibly dispersed from southern refugia, while Cambarus sp. A cf. diogenes dispersed from southern refugia not sympatric with C. polychromatus. The glacial refugia included western and southern areas of the glacial maximum; however, northern dispersal routes may be important with global climate change.
\end{abstract}

\section{Introduction}

Changes in climate patterns during the Pleistocene $(2.5$ million: 11.7 thousand years ago), which brought on the advance of glacial ice through temperate environments, had substantial effects on species distributions [1,2]. In glaciated areas, topographic diversity was reduced, drainage courses altered, and habitat changed greatly through deposits of large amounts of glacial till $[1,3]$. These vicariant events of ice advance caused species to shift ranges south or to other areas of glacial refugia [2]. As ice sheets receded, many species that had been pushed from areas covered by ice, invaded or reinvaded, and many modern species distributions in glaciated regions reflect species dispersal after glacial events [1-6]. In central United States, areas of glacial refugia existed mainly south of the glacial maximum [1]. However, glacial refugia also existed in several isolated locations such as an area north of the glacial maximum known as the Driftless Area in southern Wisconsin and northwestern Illinois, in addition to portions of the upper Missouri river drainage and to the west $[1,3,5]$.

Several authors [1, 3, 6-12] have addressed the relationship between modern species in glaciated environments and glacial refugia. Phylogeographic studies in both Europe and North America have shown substantially less heterozygosity in populations of terrestrial nonhuman mammals [7, 12], birds [8], and a semiaquatic amphibian [11] in glaciated regions compared to unglaciated regions, supporting the hypothesis of relatively recent invasions into glaciated environments. It is expected that the origins of range expansion are in the direction of increased genetic diversity. Burr and Page [1] studied the distribution of fishes of the lower Ohio 
and upper Mississippi river drainages and related distribution patterns to drainage evolution and dispersal from glacial refugia. They showed that species such as Chrosomus erythrogaster, Fundulus catenatus, and Etheostoma caeruleum have relict populations far south of their contiguous northern ranges, showing support for southern range expansion during ice advance $[1,13]$. Other fish species such as Cottus carolinae show widely separated populations in unglaciated areas on either side of the Mississippi river [13]. Absence in glaciated habitat is possibly an effect of the species being extirpated from regions during ice advance and the subsequent inability to recolonize due to lack of suitable habitat or lack of drainage connections after the ice receded $[1,13]$.

Spatial distribution and abundance of crayfishes in central United States display patterns that have allowed authors to hypothesize Pleistocene refugia $[3,6,10]$. The crayfish assemblage in Indiana is hypothesized to be similar to Illinois [3]. Page [3] discussed the distribution of the crayfishes of Illinois and inferred likely areas of glacial refugia for several species; however, these hypotheses were proposed without knowledge of crayfish distribution in Indiana. Page [3] hypothesized that species such as Procambarus acutus, Fallicambarus fodiens, and Cambarus diogenes invaded Illinois from the south; Procambarus gracilis, Orconectes immunis, and Orconectes virilis from the west; and Orconectes propinquus from the east based on distribution and abundance data. Thoma and Jezerinac [10] hypothesized a northerly dispersal of $O$. propinquus based on new distribution records from the Driftless Area [5] and dispersal from both western and southern refugia for O. immunis. Rhodes [6] attributed the disjunct populations of Orconectes indianensis in southwestern Indiana to the existence of marginal lakes that received stock of the species during glaciation.

The implication of postglacial dispersal has significant implications for aquatic organisms in light of global climate change and extant corridors providing access for nonnative and invasive species introduction. The goal of this study was to evaluate the associations of crayfish species in relation to hypothesized glacial geography and glacial refugia. A survey of crayfish occurring in aquatic and terrestrial habitats along the Wisconsin glacial edge was studied to evaluate assemblage dispersal patterns. Hypotheses concerning local species distributions were (1) that the dispersal of crayfish species into the glaciated portion of the study area was from a variety of refugia and (2) that certain species have remained limited to glaciated or unglaciated regions, while others have successfully invaded or reinvaded from both regions.

\section{Methods and Materials}

2.1. Study Locations. During Pleistocene glacial events, the majority of central North America was covered with ice (Figure 1). The south central part of Indiana was left unglaciated. The study area is located within the Indiana counties of Vigo, Clay, Owen, Greene, Sullivan, and Knox (Figure 2). The study area contains portions of four level III ecoregions defined by Omernik and Gallant [14]. The interior river lowland covers the majority of the western portion of

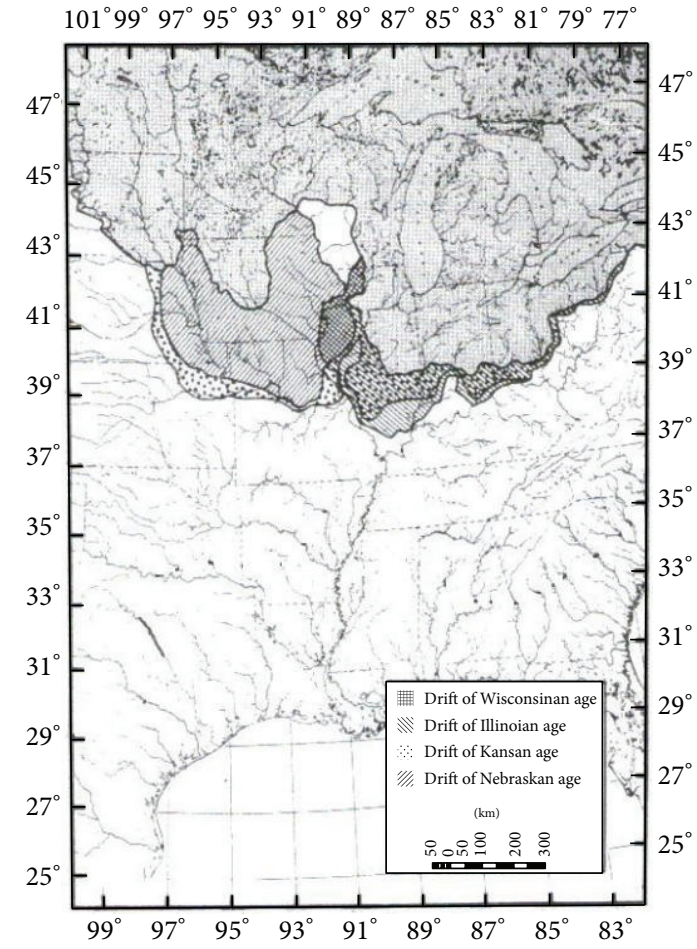

FIgure 1: Extent of glacial advance in central United States. The open area in northwestern Illinois and Southwestern Wisconsin represents the Driftless Area (adapted from Burr and Page [1]).

the study area and was glaciated by the Illinoian event [14]. Small sections of the Eastern Corn Belt and Central Corn Belt Plain ecoregions extend into the northeastern and northwestern corner of the study area. These regions were glaciated by the most recent ice advance, the Wisconsin glacial event [15]. These three regions represent the glaciated portion of the study area and are characterized by lower topographic diversity and sediments of glacial till [16]. The Interior Plateau ecoregion extends through the eastern portion of the study area and represents the unglaciated or glacial refuge portion of the study area [15]. The Interior Plateau ecoregion has topographic diversity and much of it is underlain with thick karst topography where underground caverns, sinkholes, and springs are common. Sediments are generally composed of gravel, cobble, and bedrock substrates [16].

2.2. Field Collections. Crayfish were collected during May and June, 2006, following the method of Simon [17]. Each bridge crossing over a stream or wadable water feature shown on a $1: 156,000$ unit topographic map within the boundaries of each county was marked. Thirty sites within the boundaries of each of the six counties were selected randomly from the numbered crossings using a random number generator. Crayfish were collected from each of the six counties $(N=$ 180). Sites were not weighted for either county or region. Using a random method of site selection ensured an unbiased sample of aquatic habitats and yielded a range of stream orders sampled. 


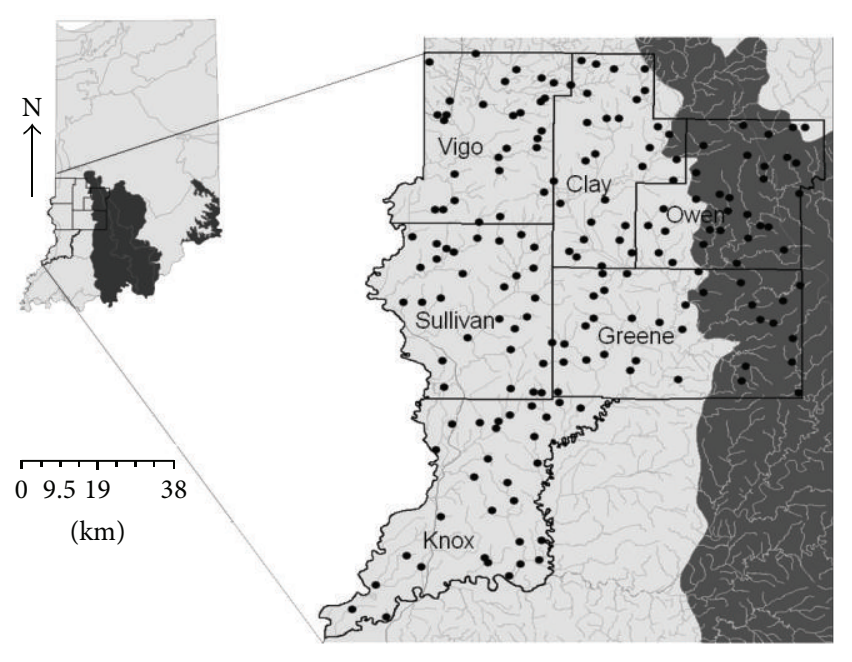

- Glaciated area

- Unglaciated area

- Study site

FIgURE 2: Glacial terminus study area in Indiana. Colors denote extent of Pleistocene glaciation. Light grey $=$ glaciated, dark grey $=$ unglaciated, and dots denote sample locations.

Aquatic crayfish assemblage was assessed through electrofishing and dip-netting and by searching under rocks by hand [18]. A smith root back-pack unit equipped with an 800 -watt generator capable of 300 volts and 3-5 amps was used. The electrofishing technique maximizes catch-per-uniteffort and is the most effective way to sample aquatic crayfish [17]. The use of other collection methods ensured a complete sample of all habitats at each location. All available habitats were sampled including riffles, runs, pools, vegetation, root mats, debris, undercut areas, and rocky areas. All crayfish collected were kept in a live well until sampling was complete. Stream sampling was conducted along a linear reach 15 times the wetted width. Sample reach length defined site length with a minimum distance of $50 \mathrm{~m}$ in smaller streams (wetted width $<3.34 \mathrm{~m}$ ) and a maximum of $500 \mathrm{~m}$ (wetted width $>33.4 \mathrm{~m}$ ) in larger streams. Length of time spent on sampling varied (300-1800 seconds) depending on the size of the stream.

Primary burrowing crayfish were collected from active burrows. Active burrows were recognized by the presence of mud exit holes usually in the shape of a "burrow chimney" and the slightly discolored or darker surrounding soil compared to lower portions of the chimney. Active burrows are free of plants and debris and have smooth inner walls. The burrows were filled with water and a toilet plunger was used to remove resident crayfish from the burrow $[17,18]$. If the crayfish could not be dislodged using the plunger method, then the burrow was excavated with a shovel and the specimen was collected by hand. Ten burrows per site were sampled in all available habitats at various distances from the waterbody when numbers permitted and a maximum of 120 minutes was spent on terrestrial sampling at each location.
For each site all crayfish specimens were collected and preserved in $70 \%$ ethanol for laboratory identification. Specimens were identified to species using Page [3], Hobbs and Jass [5], and Pflieger [19] and relative abundance was recorded for each species. All voucher specimens are deposited in the Astacology Collection of the Indiana Biological Survey Aquatic Research Center in Bloomington, Indiana.

2.3. Statistical Analysis. All statistical analyses were done using SPSS version 11.0 (SPSS Inc., Chicago, IL). For species found to occur in both the glaciated and unglaciated regions a Mann-Whitney $U$ test was run at $95 \%$ confidence levels on adult abundance at sample locations to determine if abundances differed between the two regions. Abundance of primary burrowing species was quantified by the number of individuals collected per site. Abundance of secondary and tertiary burrowing species was quantified as catch-per-uniteffort (catch/minute).

To determine patterns in species assemblages a principle components analysis (PCA) was performed using abundance data for each species occurring in the study area at each site. The PCA factor loading plots for the first two components and the factor plot for sites on the first two components were used to assess crayfish assemblages in the study area. Only species found at five or more sites within the study area were examined using PCA to limit the influence of rare species on the analysis.

Results of the distribution survey and statistical analysis were compared with range-wide distribution records of each species to determine possible relationships between distribution and glacial refugia. Crayfish range information for Illinois [3], Missouri [19], Wisconsin [5], and Ohio [10] and the distribution of Cambarus (Tubericambarus) polychromatus were assessed through the species description by Thoma et al. [20] as sources for species records and ranges.

\section{Results}

Crayfish were found to occur at 176 of the 180 sample locations. A total of ten species belonging to four genera (Procambarus, Fallicambarus, Cambarus, and Orconectes) were found in the study area [21]. Primary burrowing species included Procambarus (Girardiella) gracilis, Cambarus (Lacunicambarus) sp. A cf. diogenes, Cambarus (Tubericambarus) polychromatus, and Fallicambarus (Creaserinus) fodiens. Secondary burrowing species included Procambarus (Ortmannicus) acutus and Cambarus (Erebicambarus) laevis. Tertiary burrowing species included Orconectes (Faxonius) indianensis, Orconectes (Tricellescens) immunis, Orconectes (Crockerinus) propinquus, and Orconectes (Gremicambarus) virilis. Species distributions contained only in the glaciated study area include $P$. gracilis, $P$. acutus, C. sp. A cf. diogenes, and $O$. indianensis. The association of the remaining six species with glaciated and unglaciated regions is summarized in Table 1. Fallicambarus fodiens was found at a single unglaciated site and was only found elsewhere in glaciated sites. Orconectes immunis was found throughout the study area but was significantly more abundant in the glaciated area 
TABLE 1: Results of Mann-Whitney $U$ test for species abundance between glaciated $(N=141)$ and unglaciated $(N=35)$ regions $(\alpha=0.05)$ and proportion of sites within each region that a species was collected for the six species occurring in both regions. Superscripts denote primary (1), secondary (2), or tertiary (3) species. Abundance is measured by catch-per-minute for tertiary and secondary species and number of individuals for primary species.

\begin{tabular}{|c|c|c|c|c|c|c|}
\hline & Cambarus polychromatus ${ }^{1}$ & Fallicambarus fodiens $^{1}$ & Cambarus laevis $^{2}$ & Orconectes immunis ${ }^{3}$ & O. propinquus ${ }^{3}$ & O. virilis $^{3}$ \\
\hline $\begin{array}{l}\text { Mean abundance } \\
\text { glaciated sites }\end{array}$ & 1.43 & 0.46 & 0.024 & 0.64 & 0.38 & 0.19 \\
\hline $\begin{array}{l}\text { Mean abundance } \\
\text { unglaciated sites }\end{array}$ & 1.61 & 0.12 & 0.14 & 0.29 & 2.57 & 0.35 \\
\hline Mann-Whitney $U$ test & 2452 & 2236 & 1515 & 1496 & 1496 & 2089 \\
\hline Significance & 0.746 & 0.050 & $<0.001$ & 0.001 & 0.001 & 0.247 \\
\hline $\begin{array}{l}\text { Proportion of site } \\
\text { occurrence in } \\
\text { glaciated region }\end{array}$ & 60.0 & 2.9 & 48.6 & 53.8 & 80.8 & 37.1 \\
\hline $\begin{array}{l}\text { Proportion of site } \\
\text { occurrence in } \\
\text { unglaciated region }\end{array}$ & 66.2 & 16.6 & 3.5 & 14.3 & 38.0 & 26.2 \\
\hline
\end{tabular}

TABLE 2: Species loadings on the four principle components $(62 \%$ of variance) in the PCA analysis. PC I (20\% of variance) a gradient of species associated with unglaciated sites (negative loading) and species associated with glaciated sites (positive loading). PC II (15\% of variance) represents a gradient of Orconectes virilis to Orconectes immunis dominance.

\begin{tabular}{lcccc}
\hline \multirow{2}{*}{ Species } & \multicolumn{4}{c}{ Principle component } \\
& 1 & 2 & 3 & 4 \\
\hline C. polychromatus & -0.497 & -0.230 & 0.444 & -0.287 \\
C. sp. A cf. diogenes & 0.692 & 0.140 & 0.420 & 0.004 \\
C. laevis & -0.226 & -0.044 & 0.027 & 0.785 \\
F. fodiens & 0.177 & -0.004 & -0.760 & -0.345 \\
P. acutus & 0.543 & 0.460 & 0.305 & -0.099 \\
O. immunis & 0.319 & -0.742 & 0.065 & 0.120 \\
O. propinquus & -0.552 & 0.163 & 0.286 & -0.317 \\
O. virilis & -0.250 & 0.575 & -0.169 & 0.267 \\
\hline
\end{tabular}

$(U=1496, P=0.001)$ and occurred more frequently in glaciated sites. Cambarus laevis was found at locations within or very near to the unglaciated region and was significantly more abundant at unglaciated sites $(U=1515, P \leq 0.001)$. Orconectes propinquus was found throughout the study area but was significantly more abundant in the unglaciated sites $(U=1496, P=0.001)$ and was more common in the unglaciated sites. Orconectes virilis and Cambarus polychromatus were found in both glaciated and unglaciated regions and were not significantly more abundant in either area $(U=2489, P=0.247$ and $U=2052, P=0.746)$, respectively. The rarest species, $O$. indianensis and $P$. gracilis, occurred at less than five sites and were not used in the PCA analysis.

The scree plot of PCA eigenvalues identified four principle components that explained $62 \%$ of the variance in the species abundance variables. The PCA loadings for each species on the first four principle components are shown in Table 2. For the purposes of this study, only the first two principle components are discussed. The variable loading plot for

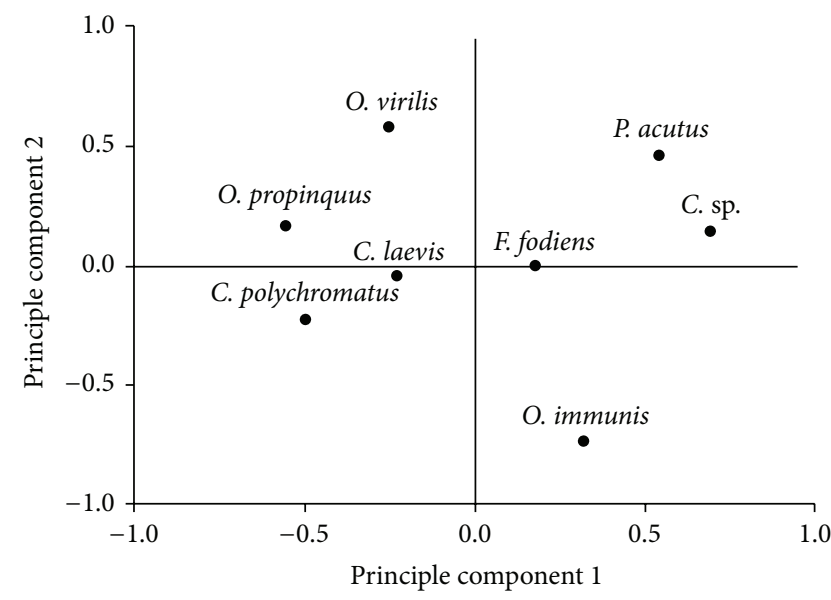

FIGURE 3: Species loading plot on the first two principle components from the PCA based on species abundances. PC I (20\% of variance) represents a gradient of species associated with unglaciated sites (negative loading) and species associated with glaciated sites (positive loading). PC II (15\% of variance) represents a gradient of Orconectes virilis to Orconectes immunis dominance. C. sp. = Cambarus spp. A cf. diogenes.

the first two principle components (35\% of variance) is shown in Figure 3. PCA component I (20\% of variance) is strongly positively associated with $P$. acutus (loading $=0.543$ ), C. sp. A cf. diogenes (loading $=0.692$ ) and more weakly negatively associated with $O$. immunis (loading $=0.319$ ) and $F$. fodiens (loading $=0.177)$. A strongly negatively associated PC I component is observed with O. propinquus (loading $=-0.552$ ) and $C$. polychromatus (loading $=-0.497$ ) and more weakly negatively associated with $C$. laevis (loading $=-0.226$ ) and $O$. virilis (loading $=-0.250$ ). A gradient between PC I represents species associated with the unglaciated region (negative loading) and glaciated region (positive loading). A strongly negative PC II is associated with $O$. immunis (loading = -0.742 ) and strongly positively associated with $O$. virilis (loading $=0.575$ ). A competitive interaction of $O$. immunis or 


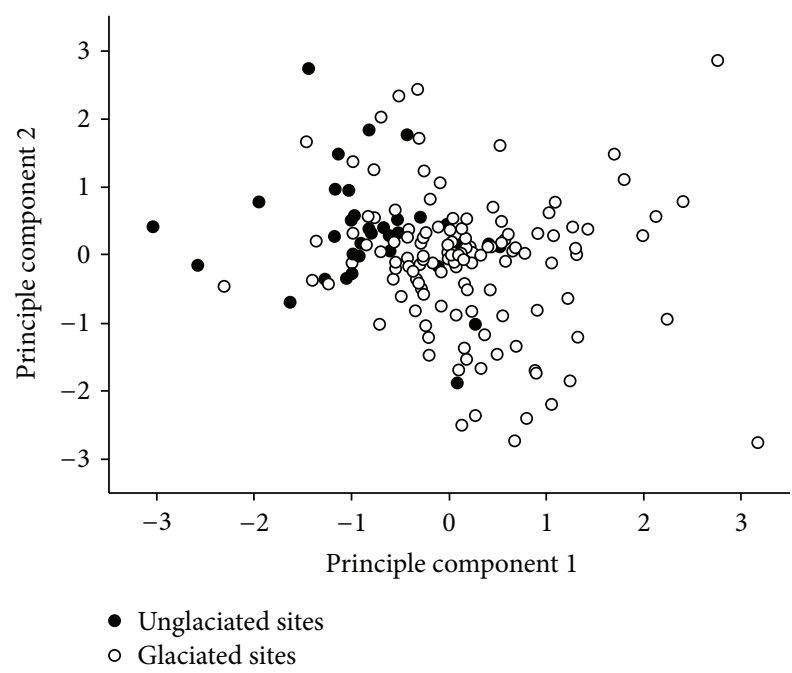

Figure 4: Plot of each sample site on the first two principle components of the PCA analysis. Dark dots are sites in unglaciated habitat, while hollow dots are in glaciated habitat.

O. virilis is represented in PC II (15\% of variance), which is a pattern noted by Bovbjerg [22] where O. immunis is dominant on soft muddy substrates and $O$. virilis is dominant on large, rock substrates.

The plot of principle component scores for each sampled reach which is based on hypothesized glacial geology is shown in Figure 4. Most of the sites from a particular area (glaciated versus unglaciated) clustered together. The PCA site plot complements the PCA factor loading plot since both analyses show that sites from the same hypothesized glacial region were associated with each other more than with sites from the other glacial region. These associations were largely a reflection of glacial geography.

\section{Discussion}

The assemblage of species in western Indiana and Illinois is potentially a result of species invasions from the south, west, and north. Upon examination of the species assemblage in Indiana, several of the hypotheses of other authors remain probable. Page [3] and Thoma and Jezerinac [10] suggested a western refuge in the upper Missouri river drainage and easterly dispersal of Orconectes immunis, Orconectes virilis, and Procambarus gracilis into current ranges. These authors also suggested a northerly advance of Procambarus acutus and Fallicambarus fodiens from areas of glacial refugia south of the glacial maximum within the Mississippi embayment. The spatial distribution of Orconectes immunis, Orconectes virilis, and Procambarus gracilis is principally west of the study area (Figure 5). These three species are known to occupy western areas that remained unglaciated, mainly in the upper Missouri river drainage $[3,19]$. Procambarus gracilis was found at a single site in the western glaciated portion of the study area but is common in eastern Illinois [3]. Orconectes immunis and O. virilis either were strongly associated with the western glaciated portion of the study area
(O. immunis) or showed no association with either glaciated or unglaciated regions. Procambarus acutus has a distribution range extending from the Great Lakes through the Gulf of Mexico and has disjunct populations along the Atlantic Coast (Figure 5). Fallicambarus fodiens has a distribution extending from the Great Lakes south through the Mississippi river embayment (Figure 5). These two species were either limited to the western glaciated region of the study area ( $P$. acutus) or highly associated with that region ( $F$. fodiens). The patterns of spatial distribution and abundance for P. acutus and F. fodiens in Indiana support the hypotheses for glacial refugia and dispersal into eastern Illinois, Indiana, and Ohio as suggested by Page [3] and Thoma and Jezerinac [10]. Fallicambarus fodiens and $P$. acutus likely invaded from areas within the Mississippi embayment while $O$. immunis, $O$. virilis, and $P$. gracilis likely invaded from the upper Missouri river drainage to the west.

Orconectes propinquus was hypothesized to exist only in glaciated environments of eastern North America [3] but was later found to occur in the unglaciated Driftless Area of southwestern Wisconsin and northwestern Illinois [5]. Based on the discovery of a population of O. propinquus in the Driftless Area, Thoma and Jezerinac [10] suggested that this species has invaded into its current range from the glacial refuge of the Driftless Area. Orconectes propinquus occurs from the Great Lakes south through Illinois and Indiana but does not occur south of Indiana (Figure 5). Orconectes propinquus was found to be widespread, abundant, and highly associated with the unglaciated region of west central Indiana. It is possible that O. propinquus invaded from both the Driftless Area and unglaciated Indiana into glaciated regions within its range. There is also the possibility that the species being assigned to $O$. propinquus in southern Indiana is actually a related but separate species belonging to the subgenus Crockerinus (T. P. Simon, unpublished data). Further examination of morphometric and molecular data is needed to establish the correct taxonomic assignment for this species. Current distribution data support invasion of O. propinquus from both the Driftless Area and the Interior Plateau in southern Indiana.

Cambarus laevis was essentially limited to the unglaciated Interior Plateau region. This species is known to occur throughout unglaciated central and southern Indiana [23]. Cambarus laevis has not successfully invaded glaciated environments. This species is associated with small spring fed streams in karst areas with large cobble and boulder substrates [23] and was not found to occur on fine substrates. Cambarus laevis is likely limited in its dispersal capabilities through adaptations to specific environmental conditions that predominate in unglaciated southern Indiana.

Orconectes indianensis has a small range in southwestern Indiana and southeastern Illinois where it is known from a few isolated watersheds. This species range is known from glaciated and unglaciated regions [3] and has a center of abundance in the unglaciated Patoka river within the Interior Plateau in Indiana [24]. Orconectes indianensis also exists in disjunct populations in several watersheds located within glaciated areas. Rhodes [6] suggested that the isolated populations of $O$. indianensis were the result of 


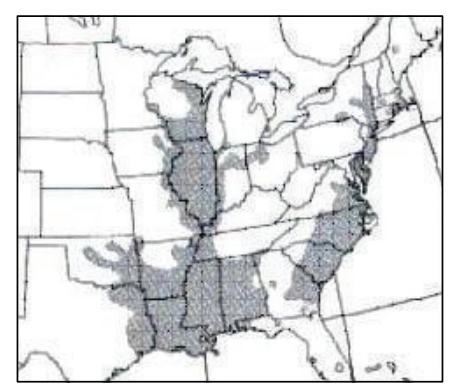

(a)

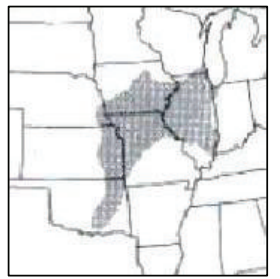

(d)

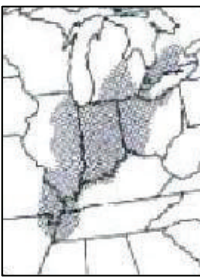

(e)

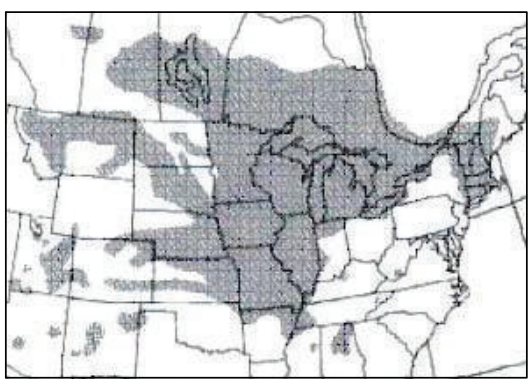

(b)

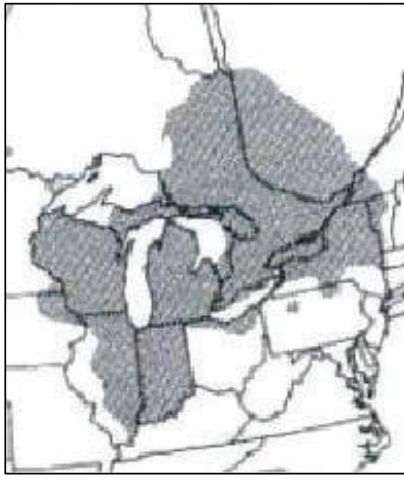

(f)

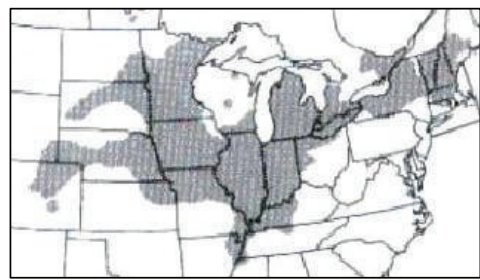

(c)

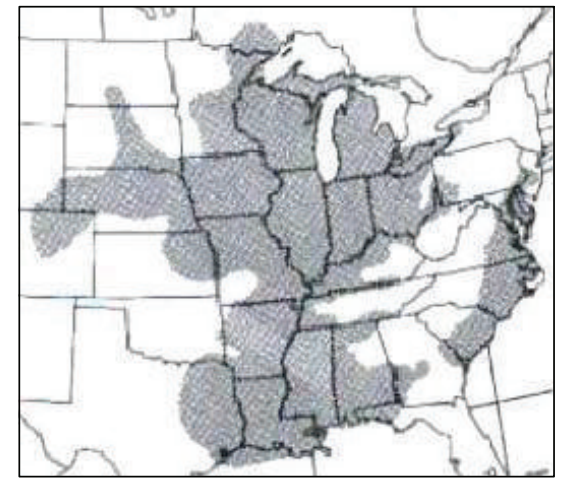

(g)

FIGURE 5: Geographic distribution of Procambarus acutus (a), Orconectes virilis (b), O. immunis (c), P. gracilis (d), Fallicambarus fodiens (e), O. propinquus (f), and Cambarus diogenes (g) in North America (adapted from Hobbs and Jass [5]).

the species persisting in temporary glacial lakes formed during Pleistocene glaciation events. After the ice sheets receded and the lakes evolved into modern drainages, $O$. indianensis was left in several disjunct populations within the glaciated environment. The population found in Busseron Creek, Indiana, is the most northerly population of $O$. indianensis. Distribution data from west central Indiana supports Rhodes' hypothesis concerning the peculiar disjunct distribution of this species [21].

Cambarus diogenes is a complex that contains several undescribed species including a wide ranging species, that is, Cambarus (Lacunicambarus) sp. A cf. diogenes [10, 20]. Thoma et al. [20] described Cambarus (Tubericambarus) polychromatus from the $C$. diogenes complex with its distribution in Indiana, Illinois, northern Kentucky, and western Ohio. It is apparent that while C. polychromatus and C. $\mathrm{sp}$. A cf. diogenes are closely related, these species did not share the same glacial refugia. Cambarus sp. A cf. diogenes was limited to the western glaciated study region, while C. polychromatus was found throughout and was highly associated with the Interior Plateau region. Distribution records for C. polychromatus suggest that the species possibly invaded from southern refugia including areas in southern Indiana and Kentucky [20]. Simon and Thoma [24], in a survey of the Patoka river in southwestern Indiana, found $C$. sp. A cf. diogenes to be absent from unglaciated regions. Page [3] suggested that $C$. diogenes invaded Illinois from southern refugia. Until the relationship of $C$. sp. A cf. diogenes can be ascertained within the $C$. diogenes complex and proper spatial distributions are established, it is difficult to speculate on the zoogeography of $C$. sp. A cf. diogenes, but clearly this species did not invade from the Interior Plateau area of Indiana.

The presence of northern dispersal corridors may be an important mechanism for aquatic species movement under global climate change scenarios. Few northern dispersal routes are available for species movement; however, crayfish species may have an advantage over sedentary mussel species or flow limited species (e.g., fish). Crayfish have the advantage of being able to cross watershed boundaries, which may be important as streams decline in flow or turn into interstitial streams.

\section{Conclusions}

Glacial events had substantial influences on spatial distributions and assemblage structure of crayfish in western Indiana. The species of crayfish in western Indiana can be grouped according to their distribution as (1) associated with glaciated regions, (2) associated with the unglaciated region, and (3) occurring throughout all regions. Of the nine species occurring in glaciated habitat in western Indiana, only $O$. propinquus possibly dispersed from a northern refuge. The Driftless Area may not have been a suitable habitat for most crayfish species during glacial ice advances, and the majority of the crayfish fauna that did not invade from areas south of the ice advance have invaded from the western refugia of the upper Missouri river. Burr and Page [1] concluded that in the Ohio river drainage the most important freshwater 
fish refugia were south and west of the ice advance. The area within the Missouri river that remained free of ice was the most important glacial refugia for the crayfish assemblage that presently occupy glaciated areas of western Indiana and eastern Illinois along with areas south of the glacial terminus of southern Indiana, Kentucky, and Illinois.

\section{Conflict of Interests}

The authors declare that there is no conflict of interests regarding the publication of this paper.

\section{Acknowledgments}

The authors thank Tarren Muskgrove, Mike Herbert, April Arroyo Monroe, and Zac Loughman, Indiana Biological Survey, for field assistance. Ashley Wilkinson and Stephanie Worden, Indiana Biological Survey, helped with data entry and data management. Dale Sparks, Indiana State University, provided helpful input into study design. This project was supported in part by the Indiana Biological Survey Aquatic Research Center and Indiana State University Department of Ecology and Organismal Biology.

\section{References}

[1] B. M. Burr and M. L. Page, "Zoogeography of fishes of the Lower Ohio-Upper Mississippi Basin," in Zoogeography of North American Freshwater Fishes, C. H. Hocutt and E. O. Wiley, Eds., John Wiley \& Sons, New York, NY, USA, 1986.

[2] G. Hewitt, "The genetic legacy of the quaternary ice ages," Nature, vol. 405, no. 6789, pp. 907-913, 2000.

[3] L. M. Page, "The crayfishes and shrimps (Decapoda) of Illinois," Illinois Natural History Survey Bulletin, vol. 33, pp. 335-448, 1985.

[4] S. D. Gerking, "Distribution of the fishes of Indiana," Investigations of Indiana Lakes and Streams, vol. 3, pp. 1-137, 1945.

[5] H. H. Hobbs III and J. P. Jass, The Crayfishes and Shrimp of Wisconsin (Cambaridae, Paleomonidae), Milwaukee Public Museum, Milwaukee, Wis, USA, 1988.

[6] R. Rhodes, "The evolution of the crayfishes of the genus Orconectes section limosus," The Ohio Journal of Science, vol. 62, pp. 65-96, 1962.

[7] J. P. Hayes and R. G. Harrison, "Variation in mitochondrial DNA and the biogeographic history of woodrats (Neotoma) of the Eastern United States," Systematic Biology, vol. 41, no. 3, pp. 331-344, 1992.

[8] J. Merilä, M. Björklund, and A. J. Baker, "Historical demography and present day population structure of the greenfinch, Carduelis chloris-an analysis of mtDNA control-region sequences," Evolution, vol. 51, no. 3, pp. 946-956, 1997.

[9] R. F. Thoma and F. R. Jezerinac, "New distribution records of crayfish (Cambarus and Fallicambarus) from Ohio, including a new subspecies record," Ohio Journal of Science, vol. 82, pp. 136$138,1982$.

[10] R. F. Thoma and R. F. Jezerinac, Ohio Crayfish and Shrimp Atlas, Ohio Biological Survey Miscellaneous Contribution No. 7, 2000.

[11] K. R. Zamudio and W. K. Savage, "Historical isolation, range expansion, and secondary contact of two highly divergent mitochondrial lineages in spotted salamanders (Ambystoma maculatum)," Evolution, vol. 57, no. 7, pp. 1631-1652, 2003.

[12] K. C. Rowe, E. J. Heske, P. W. Brown, and K. N. Paige, "Surviving the ice: northern refugia and postglacial colonization," Proceedings of the National Academy of Sciences of the United States of America, vol. 101, no. 28, pp. 10355-10359, 2004.

[13] R. M. Strange and B. M. Burr, "Intraspecific phylogeography of North American highland fishes: a test of the Pleistocene vicariance hypothesis," Evolution, vol. 51, no. 3, pp. 885-897, 1997.

[14] J. M. Omernik and A. L. Gallant, "Ecoregions of the Midwestern United States," Tech. Rep. EPA 600/3-88/037, U.S. Environmental Protection Agency, Corvallis, Ore, USA, 1988.

[15] J. L. Hough, Geology of the Great Lakes, University of Illinois Press, Urbana, Ill, USA, 1958.

[16] A. F. Schneider, "Physiography," in Natural Features of Indiana, A. A. Lindsey, Ed., pp. 40-56, Indiana Academy of Science, Indianapolis, Ind, USA, 1966.

[17] T. P. Simon, "Standard operating procedures for the collection and study of burrowing crayfish in Indiana. I. Methods for collection of burrowing crayfish in streams and terrestrial habitats," Miscellaneous Papers of the Indiana Biological Survey Aquatic Research Center 2, 2004.

[18] T. P. Simon, "Checklist of the crayfish and freshwater shrimp (Decapoda) of Indiana," Proceedings of the Indiana Academy of Science, vol. 110, pp. 104-110, 2001.

[19] W. L. Pflieger, The Crayfishes of Missouri, Conservation Commission of the State of Missouri, Jeffersonville, Mo, USA, 1996.

[20] R. F. Thoma, R. F. Jezerinac, and T. P. Simon, "Cambarus (Tubericambarus) polychromatus (Decapoda: Cambaridae), a new species of crayfish from the United States," Proceedings of the Biological Society of Washington, vol. 118, no. 2, pp. 326-336, 2005.

[21] J. L. Burskey and T. P. Simon, "Distribution of crayfish (Decapoda: Cambaridae) in West-Central Indiana, with notes on reproductive biology," Miscellaneous Papers of the Indiana Biological Survey Aquatic Research Center, vol. 6, pp. 1-18, 2007.

[22] R. V. Bovbjerg, "Ecological isolation and competitive exclusion in two crayfish (Orconectes virilis and Orconectes immunis)," Ecology, vol. 51, pp. 225-236, 1970.

[23] T. P. Simon, M. Weiseit, E. Seabrook et al., "Notes on Indiana crayfish (Decapoda: Cambaridae) with comments on distribution, taxonomy, life history, and habitat," Proceedings of the Indiana Academy of Science, vol. 114, pp. 55-61, 2005.

[24] T. P. Simon and R. F. Thoma, "Distribution patterns of freshwater crayfish (Decopoda: Cambaridae) in the Patoka River basin of Indiana," Proceedings of the Indiana Academy of Science, vol. 112, pp. 175-185, 2003. 

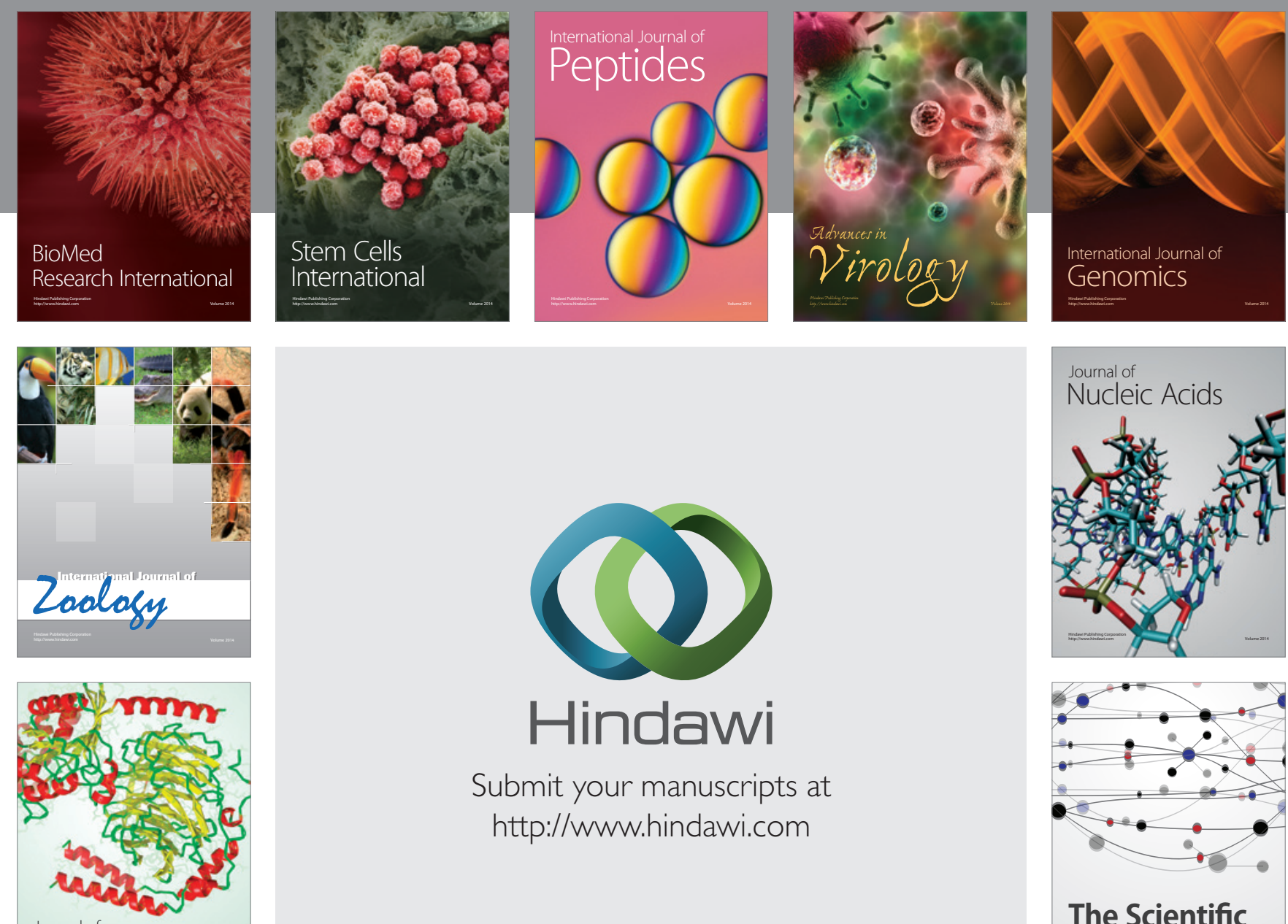

Submit your manuscripts at

http://www.hindawi.com

Journal of
Signal Transduction
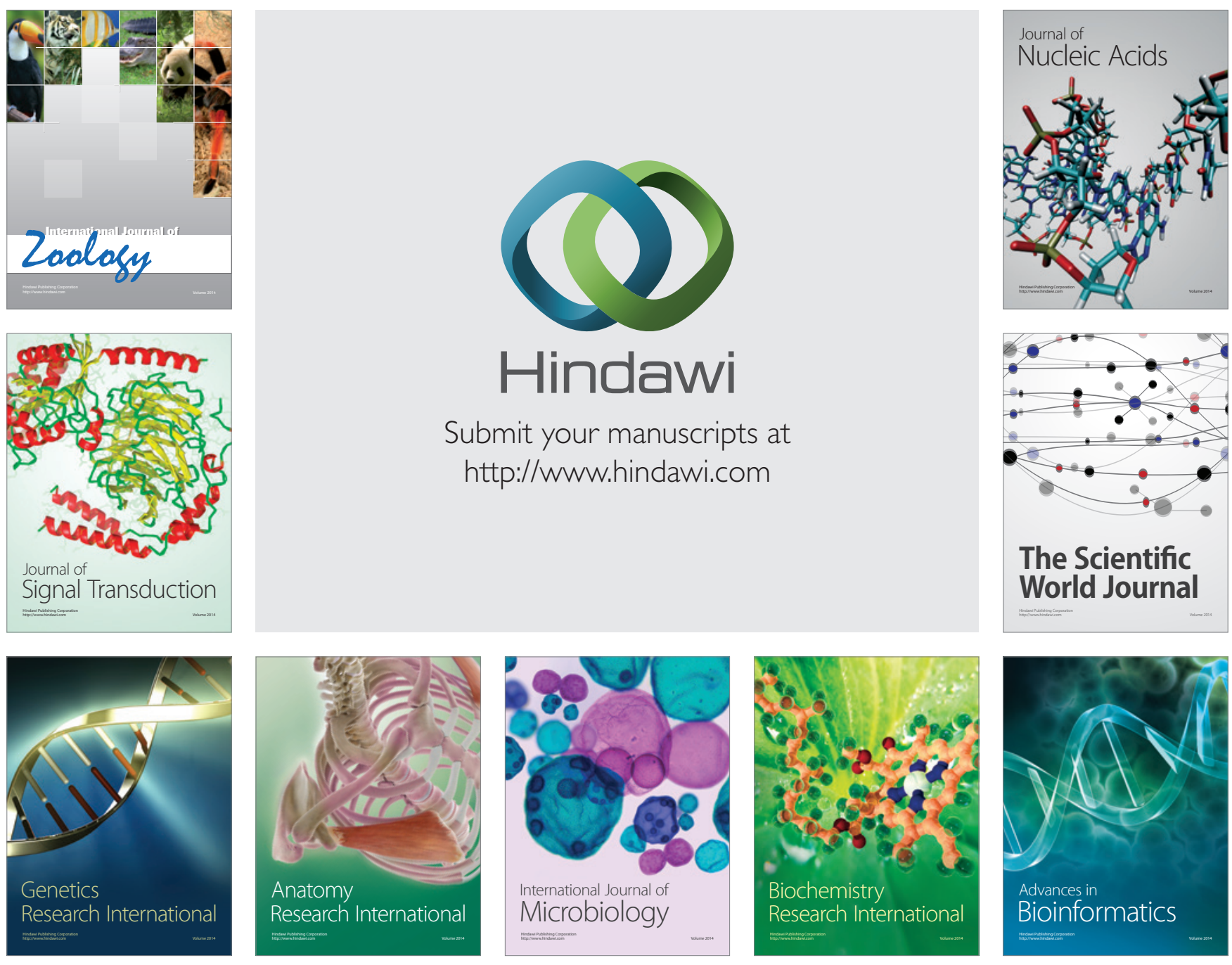

The Scientific World Journal
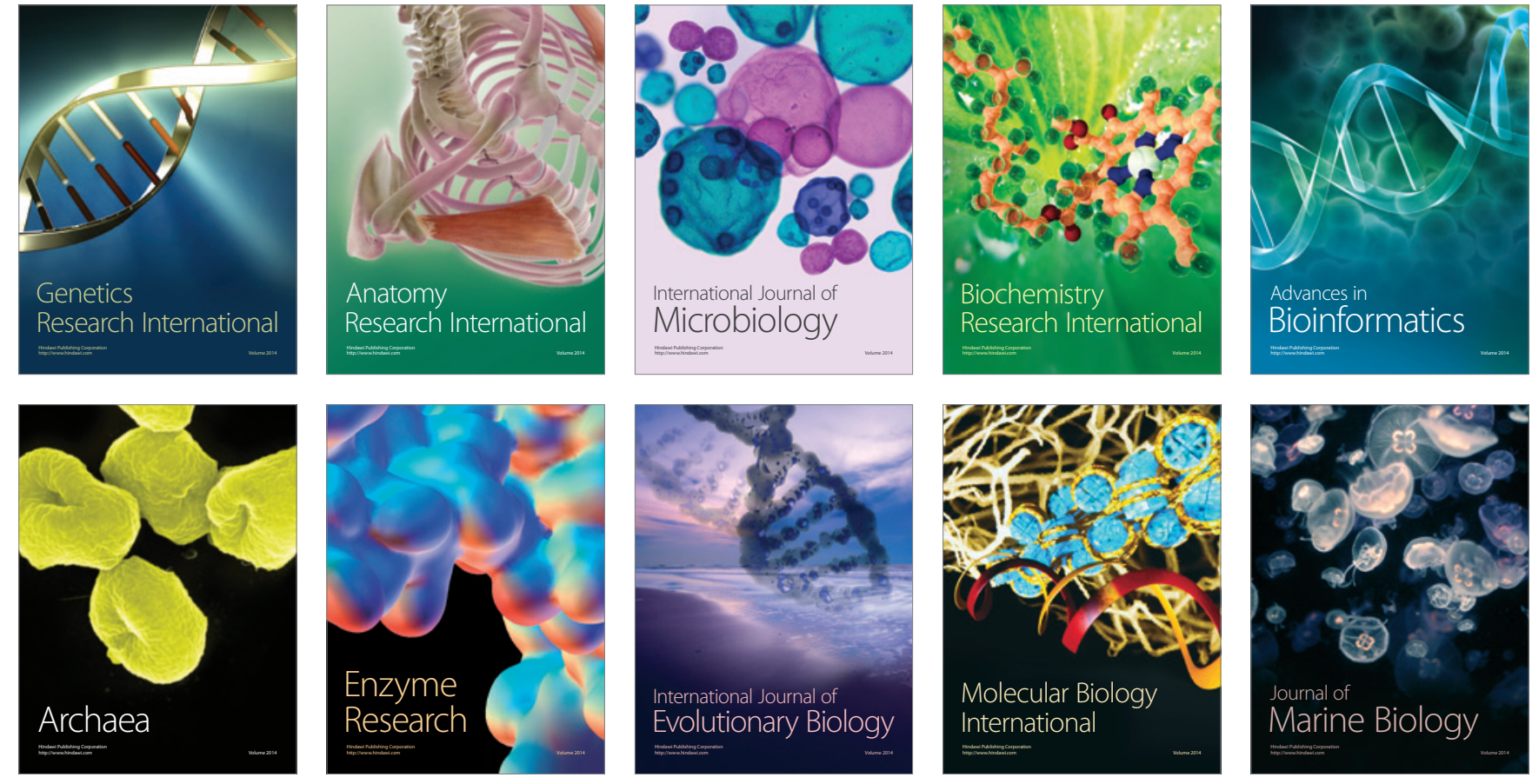